\title{
Review of the genus Harnischia Kieffer from China (Diptera, Chironomidae), with description of one new species
}

\author{
Chun-Cai Yan', Qin Guo', Ting Liu', Wei Guo', Xin-Hua Wang², Bao-Ping Pan' \\ I Tianjin Key Laboratory of Animal and Plant Resistance, Tianjin Normal University, Tianjin, 300387, PR \\ China 2 College of Life Sciences, Nankai University, Tianjin 300071, China \\ Corresponding author: Chun-Cai Yan (flyfish113@163.com)
}

Academic editor: F.L. da Silva | Received 29 August 2016 | Accepted 3 November 2016 | Published 21 November 2016 http://zoobank.org/27BD7541-95FF-434D-88AC-1E3E1348EFAB

Citation: Yan C-C, Guo Q, Liu T, Guo W, Wang X-H, Pan B-P (2016) Review of the genus Harnischia Kieffer from China (Diptera, Chironomidae), with description of one new species. ZooKeys 634: 79-99. doi: 10.3897/ zookeys.634.10323

\begin{abstract}
The genus Harnischia Kieffer, 1921 from China is reviewed and one new species, Harnischia parallela Yan \& Wang, sp. n., is described and illustrated as adult male. Harnischia okilurida Sasa is recognized as a new synonym of $H$. longispuria Wang \& Zheng. The pupae of $H$. fuscimana Kieffer and $H$. curtilamellata Malloch are redescribed from material collected in China, and an unplaced pupa is described. Key to male adults and pupae of known species of Harnischia from China is given.
\end{abstract}

\section{Keywords}

Harnischia, Chironomidae, China, new species, key

\section{Introduction}

The genus Harnischia is characterized by the morphology of the hypopygium, which is bearing a vestigial superior and inferior volsella. Previously erected by Kieffer (1921), this genus is treated as a group within Tendipes (Cryptochironomus) by Goetghebuer (1937-54). Townes (1945) proposed dividing the genus into two subgenera (Harnischia and Cladopelma). Beck and Beck (1969) also treated the genus as two subgenera. Recently, Sæther (1977) elevated Cladopelma to the genus level. The Harnischia genus

Copyright Chun-Cai Yan et al. This is an open access article distributed under the terms of the Creative Commons Attribution License (CC BY 4.0), which permits unrestricted use, distribution, and reproduction in any medium, provided the original author and source are credited. 
has a worldwide distribution (Cranston and Martin 1989; Ashe and Cranston 1990; Chaudhuri and Chattopadhyay 1990; Oliver et al. 1990; Wang et al. 1993; Sasa and Kikuchi 1995; Sasa and Ogata 1999; Wang 1999; Sæther et al. 2000; Wang 2000; Chaudhuri et al. 2001; Kawai et al. 2002, Makarchenko et al. 2005; Yan and Wang 2011; Paasivirta 2014; Murray 2015).

Wang (1999) recorded six species from China and recognized H. longispuria, which is erected by Wang et al. (1993) as a synonym of $H$. curtilamellata. After reexamination of the type specimen, $H$. longispuria has been treated as a valid species (Wang 2000, Yan and Wang 2011). To date, seven Harnischia species (H. angularis, $H$. cultriata, $H$. curtilamellata, $H$. fuscimana, $H$. japonica, $H$. longispuria and $H$. turgidula) of the genus have been recorded in China.

In this paper the genus Harnischia from China is reviewed and a description of the male adult of Harnischia parallela Yan \& Wang, sp. n., is given. Harnischia okilurida Sasa is recognized as a new synonym of H. longispuria Wang \& Zheng. The pupae of $H$. fuscimana Kieffer and $H$. curtilamellata Malloch are redescribed from China, and an unplaced pupa is described. Key to male adults and pupae of known species of Harnischia from China is provided.

\section{Material and methods}

Morphology and terminology follow Sæther (1980). The material examined consists of slide-mounted following the procedures outlined by Sæther (1969). Measurements are given as the ranges followed by a mean when four or more measurements are made. The specimens examined in this study are deposited in the collection of the College of Life Sciences, Tianjin Normal University, China (BDN).

\section{Taxonomy}

\section{Harnischia Kieffer, 1921}

Harnischia: Kieffer 1921: 273; Beck and Beck 1969: 296; Sæther 1971: 350; 1977: 89; Pinder and Reiss 1986: 326; Sasa 1989: 83; Cranston et al. 1989: 382; Langton 991: 275; Wang, 1995: 169; Rufer and Ferrington 2007: 82.

Type species. Harnischia fuscimana Kieffer, 1921.

Diagnostic characters. Adult male. The characters of superior and inferior volsellae vestigial and gonostylus broad and short, not attenuated from junction with gonocoxite will easily differentiate Harnischia adults from other genera in the subfamily Chironominae. Pupae. The medially interrupted hook row, pattern of armature on the tergites, absence of posterolateral comb on segment VIII and brush-like thoracic horn will differentiate the pupae from all the other chironomids. 


\section{Harnischia angularis Albu \& Botnariuc, 1966}

Fig. 1

Harnischia angularis: Albu and Botnariuc 1966: 54; Wang 1999: 169; Wang 2000: 644; Makarchenko et al. 2005: 410.

Harnischia hamata: Wang et al. 1993: 461; Wang 1999: 169. Syn. n.

Type locality. Romania.

Material examined. China: $1 \hat{\jmath}$, Yunnan Province, Huaping Country, Xinzhuang Town, Liangma River, 30.05.1996, sweep net, X. Wang; 10َ, Ningxia, Yinchuan City, 26.07.1987, Wang; $2 \hat{\jmath} \hat{\jmath}$, Xinjiang, Buerjin Hotel, 1.09.2002, light trap, H. Tang.

Diagnostic characters. Frontal tubercles absent. $\mathrm{R}_{1}$ without microtrichia. Tibia of front leg with a subapical seta; posterior margin of tergite IX narrowed, anal point elongated, swollen medially, sharp and slender, without lateral setae. Anal tergite bands $\mathrm{V}$-shaped, abruptly interrupted medially; gonocoxite with a projection in inner distal parts, bearing 5 strong setae and covered with microtrichia. Gonostylus slightly swollen distally, with hook-like apical teeth at the apex.
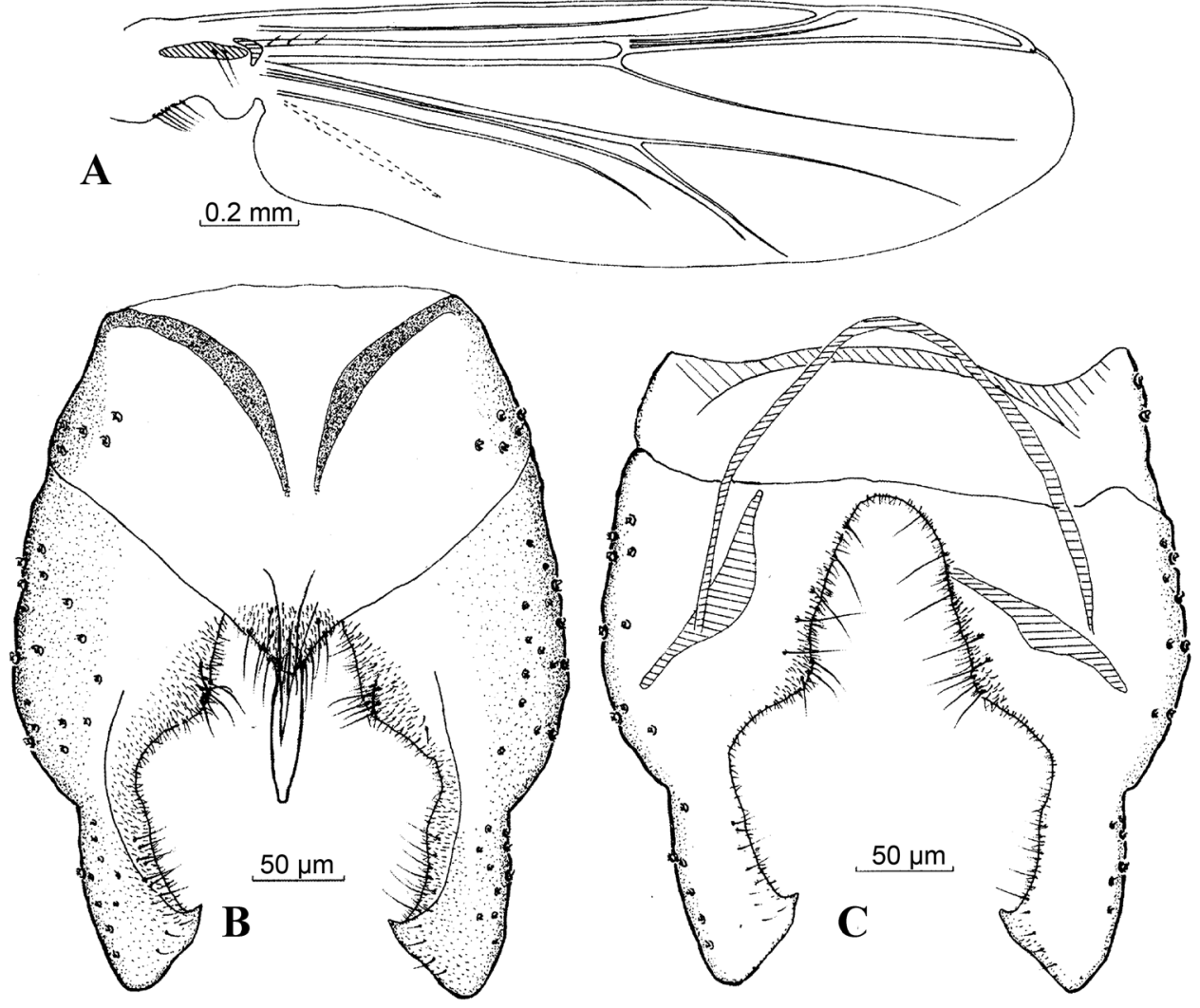

Figure I. Harnischia angularis. A Wing; Hypopygium: B (dorsal) C (ventral). 
Distribution. China (Yunnan, Ningxia, Xinjiang); Russian Far-East; Germany, Yugoslavia, Romania, Italy.

Remarks. The species can be easily distinguished by gonostylus with strong hooklike apical teeth. We agree with Wang (1999), who considered $H$. hamata Wang \& Zheng as a synonym of $H$. angularis Albu $\&$ Botnariuc.

\section{Harnischia cultriata Wang, 1999}

Fig. 2

Harnischia cultriata Wang 1999: 172.

Type locality. China (Gansu).
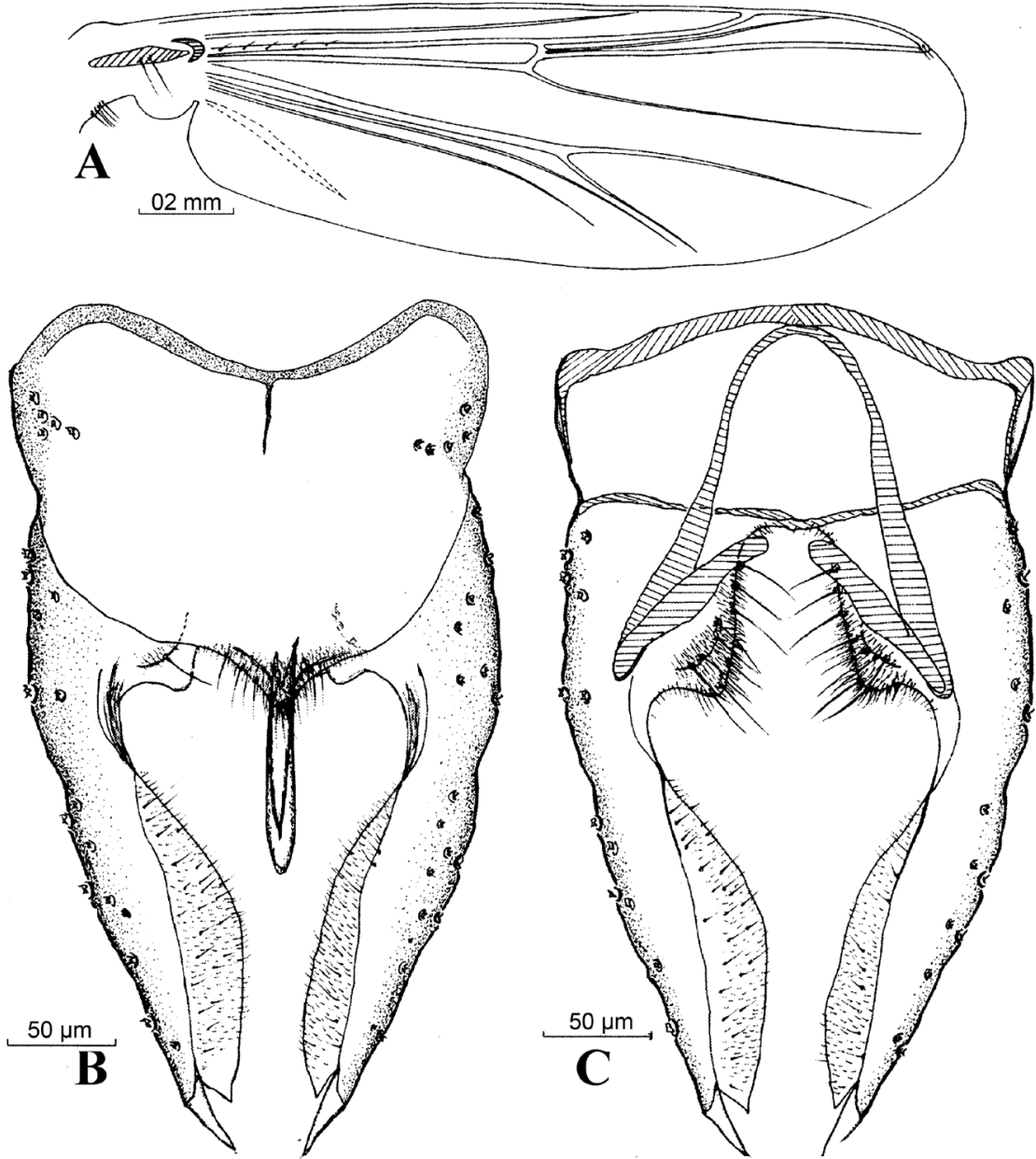

Figure 2. Harnischia cultriata. A Wing; Hypopygium: B (dorsal) C (ventral). 


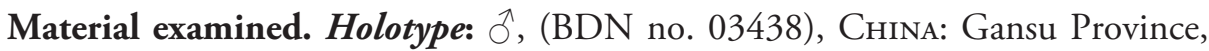
Tianshui City, Dangchuan Country, 1450 m, 8. viii. 1993, sweeping net. W. Bu.

Diagnostic characters. Frontal tubercles absent. $\mathrm{R}_{1}$ without microtrichia. Tergite IX with shoulder-like posterior margin. Anal point slightly swollen in the distal $1 / 3$, sharp at the apex, with median ridges but without lateral setae. Anal tergite bands Y-shaped, slightly flat at the bottom. Superior volsella present, bearing 4 strong setae and microtrichia. Gonocoxite with an obvious projection in distal portion of inner margin, bearing 2-3 strong setae and microtrichia; Gonostylus swollen- to knife-like at the middle, with sharp teeth at the apex.

Distribution. China (Gansu).

\section{Harnischia curtilamellata (Malloch, 1915)}

Figs 3, 4

Chironomus curtilamellata Malloch 1915: 474.

Chironomus pseudosimplex Goetghebuer 1923: 116; Edwards 1929: 390.

Chironomus (Cryptochironomus) monilis Freeman 1954a: 19.

Chironomus (Cryptochironomus) atrofasciatus Freeman 1954b: 177.

Harnischia pseudosimplex Wang S. et al. 1977: 231.

Harnischia curtilamellata: Townes 1945: 166; Sæther 1971: 347; 1977a: 88; Pinder

1978: 124; Freeman and Cranston 1980: 351; Hashimoto et al. 1981: 22; Sasa and Kikuchi 1986: 20; Sasa and Kawai 1987: 18; Ashe and Cranston 1990: 285; Cranston and Martin 1989: 270; Wang X. et al. 1993: 462; Makarchenko et al. 2005: 410; Dutta et al. 1996: 272; Wang 1999: 170; Wang 2000: 644; Chaudhuri et al. 2001: 351 .

Type locality. America (Michigan).

Material examined. ChIna: $3 \widehat{\partial} \widehat{\jmath}$, Tianjin City, Xian River, 12.06.1985, Xinhua Wang; $1 \hat{\delta}$, Jiangxi Province, Poyang Lake, Nanjishan Natural Conservation area, 12.06.2004, sweep net, Chuncai Yan. 2 ภิ $\widehat{\jmath}$, Hubei Province, Hefeng Watershed, 1200 m, 17.07.1999, light trap, Bingchun Ji; 1 đ̃, Hunan Province, Zhuzhou City, Central South Forestry University, 17.07.1995, Winjun Bu; 1 गे, Guangxi Province, Jinxiu County, 1.06.1990, Xinhua Wang; 1 đ , Hainan Province, Ledong Li Auto-

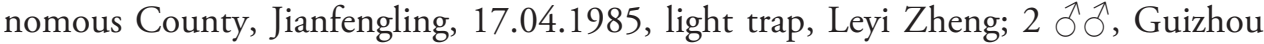
Province, Guiyang City, Huaxi area, 1050 m, 23.07.1995, light trap, Wenjun Bu; 1 o, Guizhou Province, Daozhen County, Dashahe Natural Conservation area, Fairy Cave, 600 m, 30.05.2004, light trap, Hongqu Tang; 1 đ, Guizhou Province, Jiangkou County, Fanjingshan Natural Conservation area, Black Creek, 3.06.2002, light

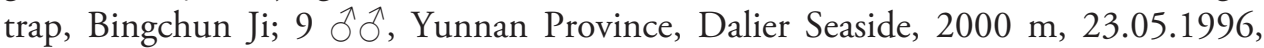
light trap, Xinhua Wang; $3 \widehat{\partial} \widehat{\partial}$, Yunnan Province, Eryuan County, Niujie Town, Futian, Meici River, 2262-2332 m, $14.5^{\circ} \mathrm{C}, 24.05 .1996$, light trap, Changfa Zhou and Beixin Wang; $1 \widehat{\partial}$, Yunnan Province, Lijiang City, Shigu Town, Chongjiang Ri- 

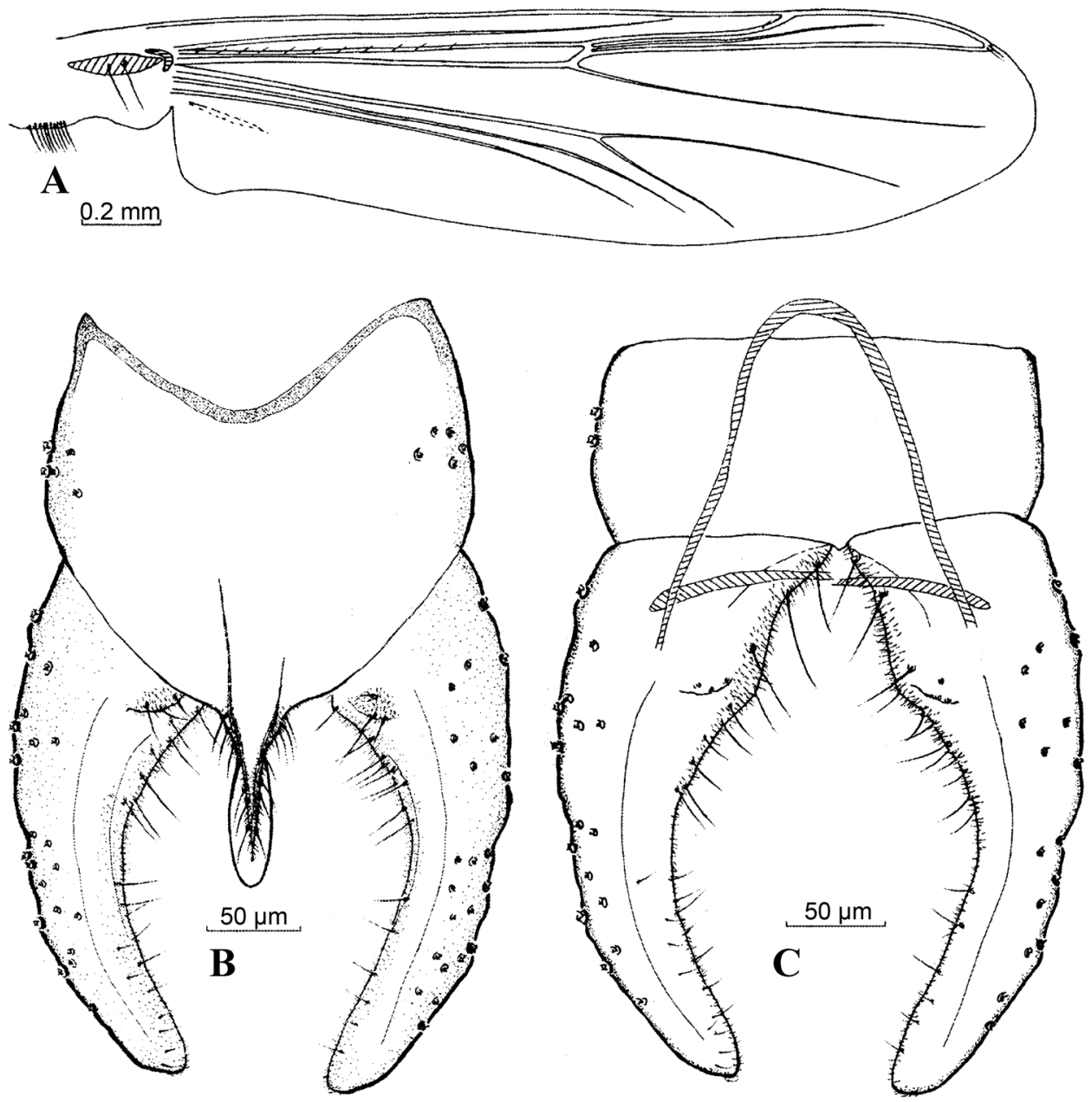

Figure 3. Harnischia curtilamellata. A Wing; Hypopygium: B (dorsal) C (ventral).

ver, 25.05.1996, light trap, Changfa Zhou; 1 गे, Yunnan Province, Wuding County, Mashan Stream, 1.06.1996, Xinhua Wang; 1 đo, Yunnan Province, Zhongdian Martyr

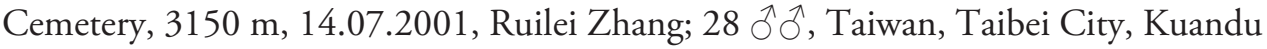
Wetland, 20.10.1988, Kanjin Ma.

Diagnostic characters. Male. (Fig. 3A-C) Frontal tubercles elliptical or rounded, sometimes absent. Anal point wide, shrunken and slender at the base, distally swollen like a bubble, semi-transparent, with median ridges, bearing lateral setae and microtrichia. Phallapodeme long and slender. Gonostylus widest at the base, curved in the middle and gradually tapering distally, round and blunt in the apex. Pupa. (Fig. $4 \mathrm{~A}-\mathrm{F})$ Sternite I with a pair of spinose anterolateral and anteromedian tubercles on each side; tergites III-VI with narrow, posterior robust spines; hook row medially interrupted; segment VIII without comb or spurs. 


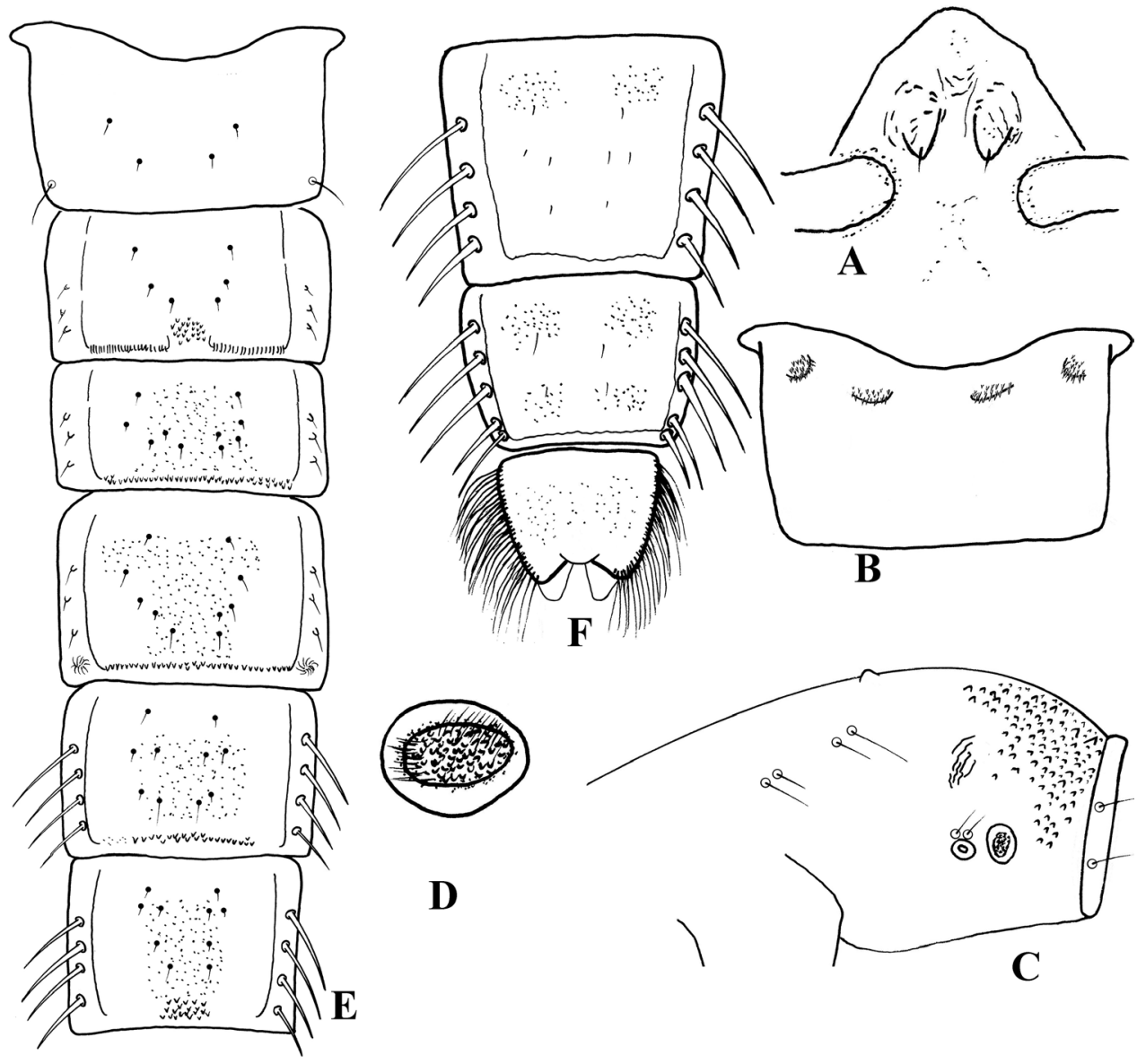

Figures 4. Harnischia curtilamellata. Pupae. A frontal apotome B sternite I C thorax, lateral view D basal ring $\mathbf{E}$ tergites I-VI $\mathbf{F}$ tergite VII-VIII and anal lobe.

Materials examined. ChInA: 1P, Guangxi Zhuang Autonomous Region, Guilin City, Dingjiang County, Yangiiangtou town 6.04.2015. Wenbin Liu. 1P, China: Shandong Province, Jining City, Weishan County, Weishan Island 4.10.2015. Wenbin Liu. 5P, China: Guangdong Province, Maoming City, Linchen River 27.11.2013. Jun Liu.

Description. Pupa $[\mathrm{n}=8$ ] Total length 3.2-4.9 mm. Cephalothorax brown; abdomen pale brownish.

Cephalothorax (Fig. 4A, C-D). Frontal setae 20-30 $\mu \mathrm{m}$ long, fine, arising subapically from conical, 50-100 $\mu \mathrm{m}$ long cephalic tubercles. Thoracic horn plumose, with numerous fine branches; basal ring oval. Thorax granulose dorsally, more densely granulose anteriorly. Prealar tubercle low, rounded. Scutal tubercle prominent. Wing sheath without nose; pearl row absent. Two short precorneals, 2 short antepronotals and 4 dorsocentrals present. Lengths of dorsocentrals $(\mu \mathrm{m})$ : 50-75, 38-50, 56-63, 25-40. 
Abdomen (Fig. 4B, E-F). Tergite I (Fig. 4E) bare; II with posteromedian group of small points; III-VI with narrow, transverse, posterior band of robust spines; VII with a pair of anterior patches fine shagreen; VIII with a pair of anterior and posterolateral patches of shagreen. Hook row widely interrupted medially. Conjunctives bare. Pedes spurii A present on segment IV; pedes spurii B present on segment I. Sternite I (Fig. 4B) with a pair of spinose anterolateral and anteromedian tubercles each sides. Segment VIII without posterolateral comb or spurs. Segment II-IV with 3 strong L setae situated on tubercles; V-VII with 4 LS setae, VIII with 5 LS setae.

Anal lobe (Fig. 4 F) 1.44-2.20 $\times$ as long as broad, with complete fringe of 31-51 lamelliform setae. Genital sac 125-220 $\mu \mathrm{m}$ long, extending beyond anal lobe.

Distribution. China (Tianjin, Jiangxi, Hubei, Hunan, Guangxi, Hainan, Guizhou, Yunnan, Taiwan); Japan; Thailand; India; Russian Far-East; Europe; North America; Africa region (South Africa, Sudan, Sebegal, Zaire); Australian Region (Australia).

Remarks. The Chinese specimens mainly agree with the description of Langton (1991), but the color of spinose anteromedian tubercles of sternite I is lighter than from Europe. Based on original descriptions and figures, the record of Harnischia pseudosimplex Goetghebuer in China (Hubei province; Wuhan City) by Wang S. et al. (1977: 231, fig. II: 15) should be Harnischia curtilamellata (Malloch).

\section{Harnischia fuscimana Kieffer, 1921}

Fig. 5

Harnischia fuscimana: Kieffer 1921b: 69; Goetghebuer 1937-54: 48; Sæther 1971:

348; Wang S. et al. 1977: 231; Fittkau and Reiss 1978: 432; Wang 2000: 644;

Makarchenko et al. 2005: 410.

Type locality. Poland

Diagnostic characters. Male. Body pale green. Anal point taper-shaped and tapering towards the sharp apex, bearing lateral setae and microtrichia. Gonostylus thick, blade-shaped projection. Superior and inferior volsellae absent. The conjunction of gonostylus and gonocoxite shrunken and obviously tapered. Gonostylus short, with a weak projection at base, almost as long as gonocoxite. Pupa. (Fig. 5A-F) Sternite I with only spinose anterolateral tubercles; hook row medially interrupted; segment VIII without comb or spur.

Materials examined. China: 1P, Guangdong Province, Maoming City, Baowei town 10.12.2012. Hongqu Tang.

Description. Pupa $[\mathrm{n}=1]$ Total length $6.55 \mathrm{~mm}$. Cephalothorax brown; abdomen pale brownish.

Cephalothorax (Fig. 5A, C-D). Frontal setae $45 \mu \mathrm{m}$ long, fine, arising subapically from conical, $130 \mu \mathrm{m}$ long cephalic tubercles. Thoracic horn (Fig. 5C) plumose, with numerous fine branches; basal ring oval. Thorax granulose dorsally, more densely granulose anteriorly. Prealar tubercle low, rounded. Scutal tubercle prominent. Wing 

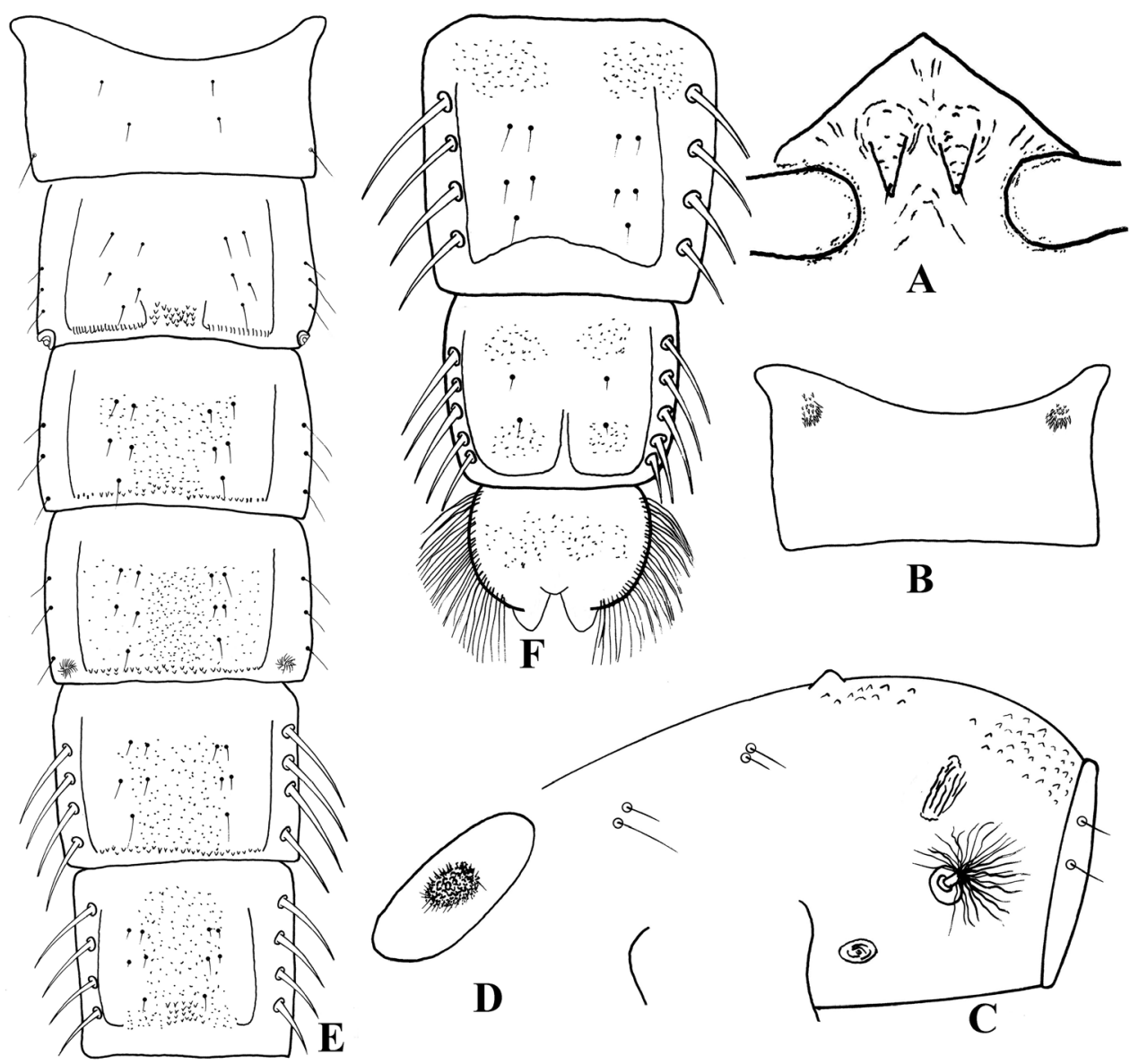

Figures 5. Harnischia fuscimana. Pupae. A frontal apotome B sternite I C thorax, lateral view D basal ring $\mathbf{E}$ tergites I-VI $\mathbf{F}$ tergite VII-VIII and anal lobe.

sheath without nose; pearl row absent. Two short precorneals, 2 short antepronotals and 4 dorsocentrals present.

Abdomen (Fig. 5B, E-F). Tergite I (Fig. 5E) bare; II with posteromedian group of small points; III-VI with transverse, posterior band of spinules; VII with a pair of anterior patches fine shagreen; VIII with a pair of anterior and posterolateral patches of shagreen. Hook row widely interrupted medially. Conjunctives bare. Pedes spurii A present on segment IV; pedes spurii B present on segment I and II. Sternite I (Fig. 5B) with spinose anterolateral tubercles. Segment VIII without posterolateral comb or spur. Segment II-IV with 3 strong L setae; V-VII with 4 LS setae, VIII with 5 LS setae.

Anal lobe (Fig. 5F) $1.74 \times$ as long as broad, with complete fringe of 70 lamelliform setae. Genital sac $300 \mu \mathrm{m}$ long, extending beyond anal lobe.

Distribution. China (Hubei), Russian Far East; Afghanistan; Lebanon; Europe (Gemary, Poland, Yugosiavia, Romania, France, Belgium, Spain, Italy). 
Remarks. The species was recorded in China by Wang S. (1977). The Chinese specimens of pupal stages mainly agree with the description of Langton (1991), but fringe setae of anal lobe of specimens from China (70) more than from Europe (45-59).

\section{Harnischia japonica Hashimoto, 1984}

Fig. 6

Harnischia japonica: Hashimoto 1984: 262; Wang et al. 1993: 461; Sasa et al. 1988: 32; Sasa 1990a: 31; Sasa 1993: 72; Wang 1999: 172; Wang 2000: 644; Makarchenko et al. 2005: 410.

Type locality. Japan.

Material examined. China: 1 $\widehat{\partial}$, Fujian Province, Wuyi Mountain Natural Conservation area, 24.04.1993, light trap, Xinhua Wang; $3 \hat{\jmath} \delta$, Shandong Province, Yantai City, Mouping, Kunyu Mountain, Dianhou, 24.08.1987, Hongyang Li; $2 \lesssim \widehat{\jmath}$, Guangxi Province, Longsheng County, Sanmen Town, 27.05.1990, Xinhua Wang. Korea: $1 \hat{\gamma}$, 20.05.2000, Dr. T.S. Chon.
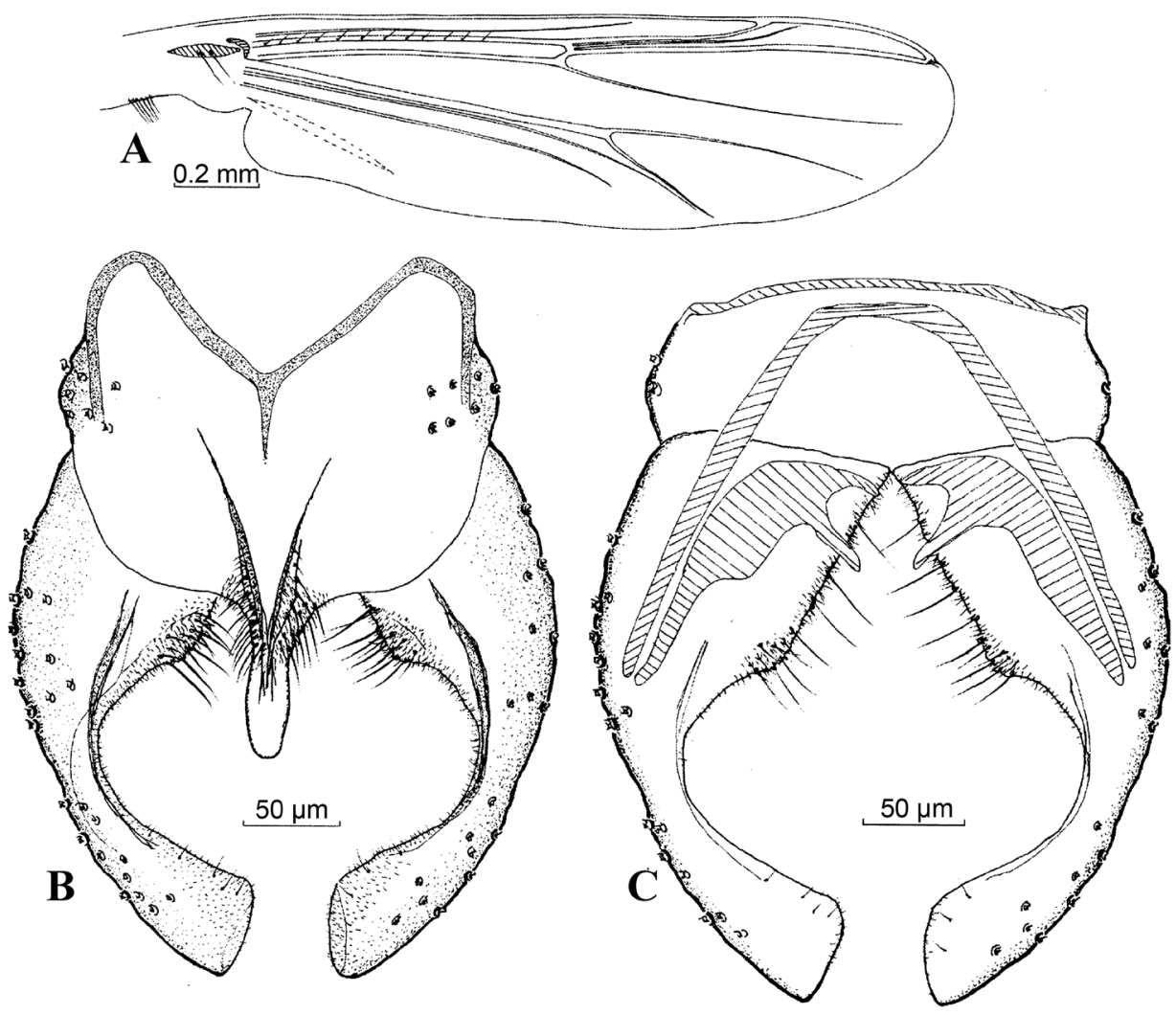

Figures 6. Harnischia japonica. A Wing; Hypopygium: B (dorsal) C (ventral). 
Diagnostic characters. Ventral tergites I-IV each terminal with brown band. $\mathrm{R}_{1}$ without microtrichia. Tergite IX with shoulder-like posterior margin. Anal point slightly swollen in the distal $1 / 3$, round and blunt at the apical and with median ridges, bearing lateral setae and microtrichia, stretching to the middle of tergite IX. Anal Tergite bands Y-shaped. Inner margin of gonocoxite with a small protrusion in distal, bearing setae and microtrichia. Gonostylus slender at the base, swollen and truncated apically.

Distribution. China (Fujian, Shandong, Guangxi); Korea; Japan; Russian Far East.

\section{Harnischia longispuria Wang \& Zheng, 1993}

Fig. 7

Harnischia longispuria: Wang and Zheng 1993: 459; Wang 1999: 170; Wang 2000: 644. Harnischia okilurida: Sasa 1993: 127 Syn. n.
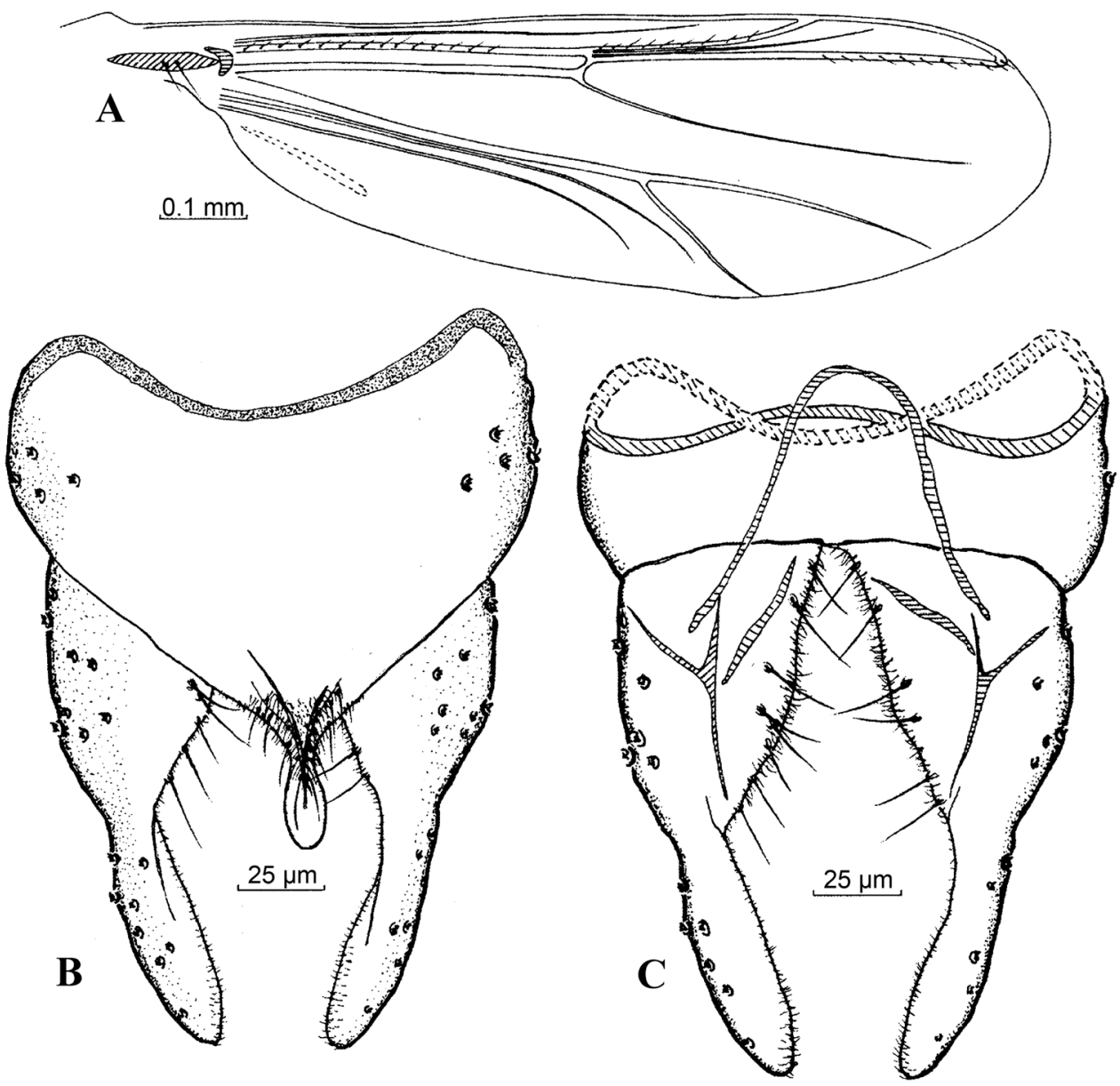

Figures 7. Harnischia longispuria. A Wing; Hypopygium: B (dorsal) C (ventral). 
Type locality. China (Hainan).

Material examined. China: Holotype, $ð$ (BDN No. 05224), Hainan Province, Ledong Li Autonomous County, Jianfeng town, 17.05.1988, light trap, Leyi Zheng. JaPAN: Holotype (Harnischia okilurida Sasa), ô (No. 246: 10), at the side of a dam of Yona River, Lake Nawagaike, 20.05.1993, insect net.

Diagnostic characters. Thorax yellow with dark brown spots; AR 0.98, frontal tubercles absent; postrior margin of tergite IX triangular and cone-like; anal point constricted at base and swollen distally, with median ridges, bearing setae and microtrichia; anal tergite bands V-shaped, slightly flat at bottom; a fusion of gonostylus and gonocoxite obviously constricted, gonostylus straight, rod-like, both sides almost parallel, round and blunt at apex, without conspicuous short setae in inner margin.

Distribution. China (Hainan); Japan.

Remarks. Wang (1999) treat $H$. longispuria Wang \& Zheng as a synonym of $H$. curtilamellata (Malloch). After re-examining, the specimens of $H$. longispuria Wang \& Zheng, (which should be H. okilurida Sasa), it currently should be a valid species. However, H. okilurida Sasa (December 1993) described later than H. longispuria Wang \& Zheng (October 1993), is consequently considered as a new synonym of $H$. longispuria Wang \& Zheng.

\section{Harnishia parallela Yan \& Wang, sp. n.}

http://zoobank.org/CC353CD1-D115-4F2D-85BD-19446E7C2B00

Fig. 8

Diagnostic characters. The new species is distinguished by the following combination of characters: $R_{1}$ without microtrichia; front tibia with a subapical seta; tergite IX broadly triangular, with 26 setae (13 on each side); anal point parallel-sided, distinctly extended basally as a V-shaped form; without lateral and dorsal setae; phallapodeme wide and large; gonocoxite blunt and rounded apically, with 2 broad dorsal lobes; gonostylus with a small dorsal basal lobe bearing setae.

Type material. Holotypes: $\widehat{\partial}$ (BDN No. 24949), China: Xinjiang burqin hotel $\left(49.41^{\circ} \mathrm{N}, 86.59^{\circ} \mathrm{E}\right), 1.09 .2002$, Light trap, H. Tang; Paratype: 3 $\sigma^{\widehat{\lambda}}$ (BDN No. 24900, 24915, 24968), as holotypes.

Etymology. The specific name, from Latin parallela, refers to anal point parallel-sided.

Description. Male imago [ $\mathrm{n}=4$, unless otherwise stated] Total length 3.55-3.68, $3.63 \mathrm{~mm}$; wing length $1.83-1.98,1.93 \mathrm{~mm}$; total length / wing length 1.86-1.94, 1.88; wing length /length of profemur 2.38-2.54, 2.47.

Coloration. Thorax yellow brown, with dark brown spots. Femora of front legs yellow green, tibia dark brown, tarsus 1 dark brown except for yellow brown in basal $1 / 2$ yellow brown, tarsi 2-4 dark brown; femora and tibiae of mid and hind legs yellow green, tarsi $1-4$ yellow brown to dark brown, tarsi 5 black brown. Abdomen. Tergites I-IV yellow brown, each terminal with light brown, tergites V-VIII; hypopygium dark brown. 

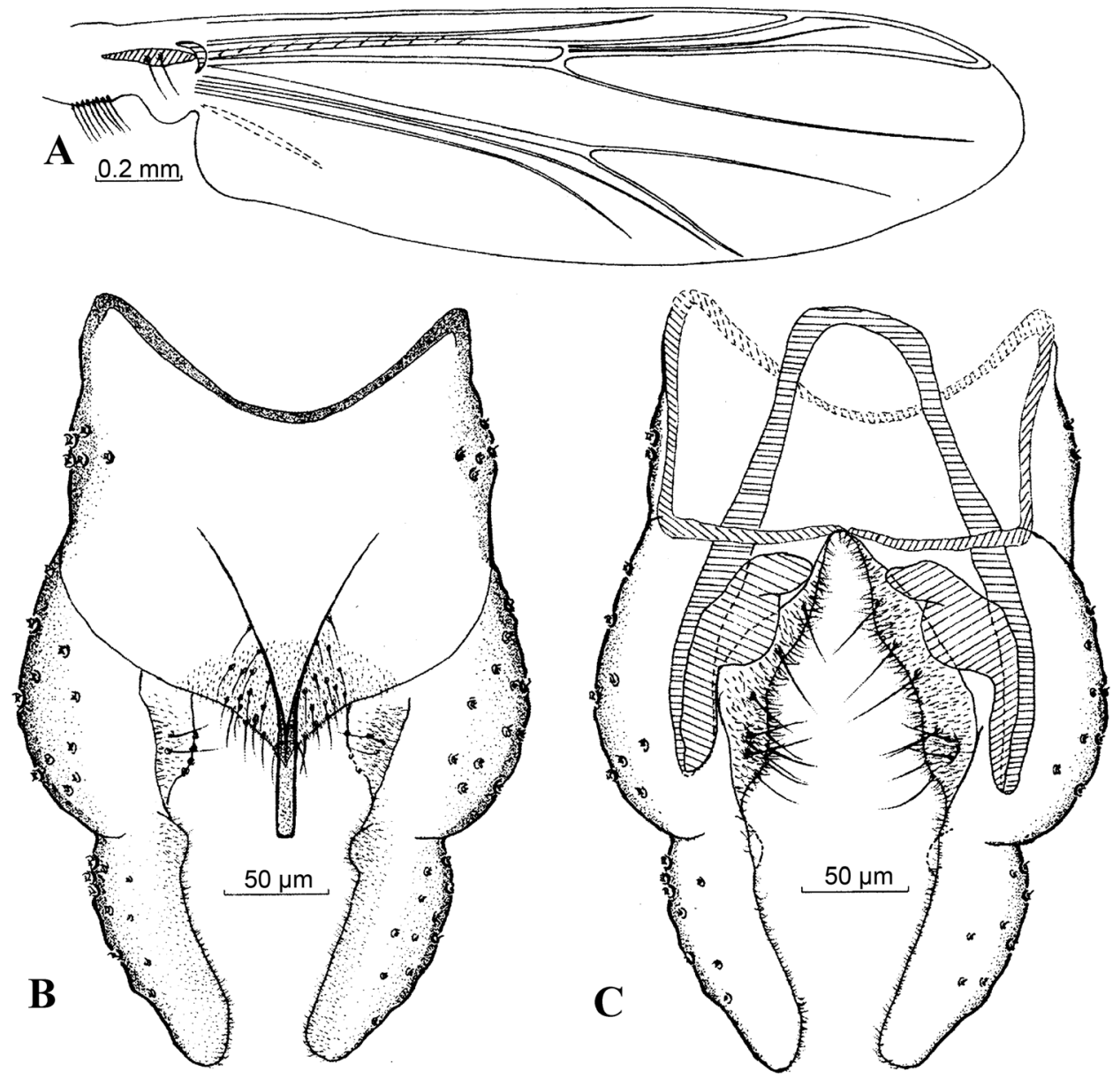

Figures 8. Harnischia parallela Yan \& Wang, sp. n. A Wing; Hypopygium: B (dorsal) C (ventral).

Head. AR: 2.06-2.24, 2.17. Ultimate flagellomere 660-740, $710 \mathrm{~mm}$. Frontal tubercles absent. Temporal setae 12-16, 14, including 3-4, 3 inner verticals; 4-5, 5 outer verticals; and 5-7, 6 postorbitals. Clypeus with 13-16, 15 setae. Tentorium 100-130, $117 \mathrm{~mm}$ long, 28-33, $31 \mathrm{~mm}$ wide. Palpomere lengths $(\mu \mathrm{m}): 40-45,43(3)$; $42-50,47(3) ; 122-150,137(3) ; 163-170,165(3) ; 235-245(2)$; palp segment $5^{\text {th }} /$ $3^{\text {rd }}: 1.57-1.69(2)$.

Thorax. Antepronotum with 2-5, 4 setae, acrostichals 7-7, 7, dorsocentrals 9-11, 10, prealars 4-4, 4. Scutellum with 6-9, 7 setae.

Wing (Fig. 8A). VR: 1.11-1.13, 1.12. $\mathrm{R}$ with 8-11, 10 setae. $\mathrm{R}_{1}$ without setae. $\mathrm{R}_{4+5}$ with 1-2, 1 seta. Brachiolum with 2-2, 2 setae. Squama with 7-11, 9 fringed setae.

Legs. Front tibia with a subapical seta, 82-90, $87 \mathrm{~mm}$. Mid legs with 2 spur, 15-20, $18 \mathrm{~mm}$ and 22-28, $26 \mathrm{~mm}$, comb with 20-28, 25 teeth, 8-10, $9 \mathrm{~mm}$ long. Spurs of 
Table I. Lengths (in $\mu \mathrm{m})$ and proportions of adult male legs in $H$. parallela Yan \& Wang, sp. n. $(\mathrm{n}=4)$.

\begin{tabular}{c|c|c|c|c|c|c|c|c}
\hline & $\mathbf{f e}$ & $\mathbf{t i}$ & $\mathbf{t a}_{\mathbf{1}}$ & $\mathbf{t a}_{\mathbf{2}}$ & $\mathbf{t a}_{\mathbf{3}}$ & $\mathbf{t a}_{4}$ & $\mathbf{t a}_{5}$ & $\mathbf{L R}$ \\
\hline \multirow{2}{*}{$\mathbf{p}_{\mathbf{1}}$} & $730-820$, & $440-480$, & $1000-1020$ & $530-550$, & $370-390$, & $270-270$, & $130-150$, & $2.13-2.27$, \\
& 783 & 460 & $1010(3)$ & $540(3)$ & $383(3)$ & $270(3)$ & $140(3)$ & $2.18(3)$ \\
\hline \multirow{2}{*}{$\mathbf{p}_{2}$} & $700-770$, & $580-650$, & $390-430$, & $190-200$, & $140-160$, & $100-110$, & $80-90,85$ & $0.63-0.67$, \\
& 745 & 625 & 413 & 198 & 150 & 103 & & 0.66 \\
\hline \multirow{2}{*}{$\mathbf{p}_{\mathbf{3}}$} & $800-900$, & $760-830$, & $580-640$, & $300-320$, & $260-280$, & $150-170$, & $110-110$, & $0.76-0.77$, \\
\hline
\end{tabular}

hind tibia 18-22, $20 \mathrm{~mm}$ and 25-32, $29 \mathrm{~mm}$ long, comb with 50-60, 54 teeth, 9-10, $10 \mathrm{~mm}$ long. Tarsus I of mid leg with 2-4, 3 sensilla chaetica. Lengths (in $\mu \mathrm{m}$ ) and proportions of thoracic legs as in Table 1.

Hypopygium (Fig. 8B-C). Tergite IX broadly triangular at base, bearing 26-32, 29 setae. Laterosternite IX with 4-6, 5 setae. Anal point 58-70, $65 \mathrm{~mm}$ long, parallelsided, without dorsal and lateral setae. The basal ridge of anal point stretched towards the middle of tergite IX. Anal tergite bands transversally extended and concave medially. Phallapodeme 108-120, $116 \mathrm{~mm}$ long. Transverse sternapodeme 35-60, $47 \mathrm{~mm}$ long. Gonocoxite 130-147, $138 \mathrm{~mm}$ long, with two broad dorsal lobes, one basal and one distal, distal lobe with 8 strong setae; basal inner margin with 4 stout setae; gonostylus 117-120,119 mm long, blunt and rounded apically, with a distinct basal inner protrusion, rows of setae along inner margin absent. HR: 1.12-1.24, 1.18; HV: 3.03-3.12, 3.05.

Distribution. China (Xinjiang).

Remarks. H. parallela Yan \& Wang, sp. n. can be easily be separated from all other members of the Harnischia genus the morphological characters of: anal tergite band (transversally concave medially); anal point (parallel-sided); gonocoxite (bearing two broad dorsal lobes: 1 basal and 1 distal); gonostylus (with a small dorsal lobe at base).

\section{Harnischia turgidula Wang \& Zheng, 1993}

Fig. 9

Harnischia turgidula: Wang and Zheng 1993: 460; Wang 1999: 172; Wang 2000: 644; Makarchenko et al. 2005: 410.

Type locality. China (Guangdong).

Material examined. China: $4 \hat{\partial} \widehat{\partial}$, Hunan Province, Yizhang County, Mang Mountain Natural Conservation area, Elevation 1200 m, 22.07.2004, Light trap, C. Yan; $4 \hat{\jmath} \widehat{\partial}$. Hunan Province, Yizhang County, Mang Mountain Natural Conservation area, Elevation 1280 m, 22.07.2004, Sweep net, Yan; 1 Oे, Guangdong Province, Fengkai County, Heishiding Mountain Natural Conservation area, 20.04.1988, 

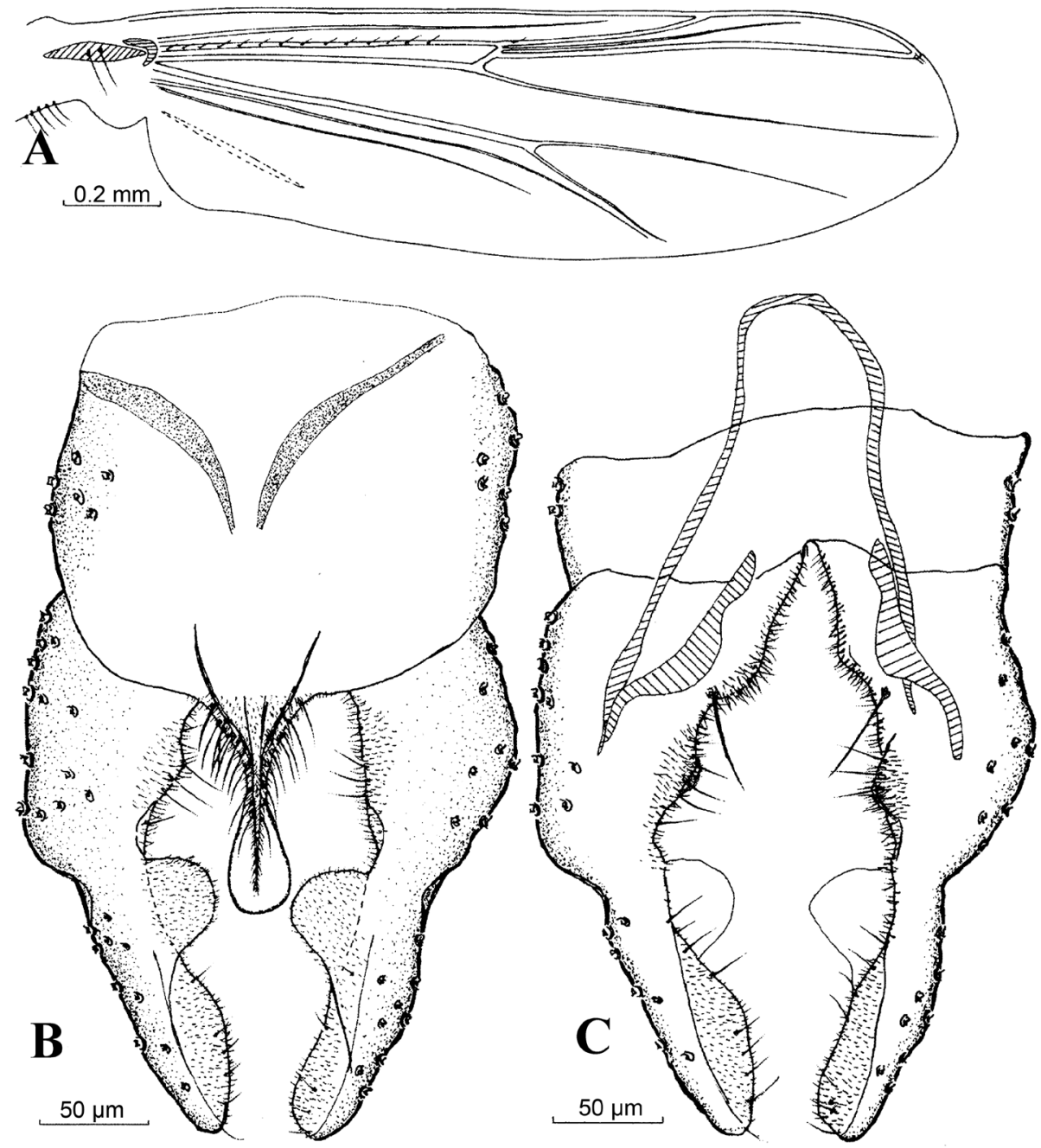

Figures 9. Harnischia turgidula. A Wing; Hypopygium: B (dorsal) C (ventral).

Sweep net, Wang; 1 đे, Guangxi Province, Longsheng, 26.05.1990, Wang; 1 đ, Yunnan Province, Dali City, Yinqiao Town, Elevation 2000 m, 21.05.1996, Water net, Wang.

Diagnostic characters. AR 1.73-2.09. Frontal tubercles absent or small. $\mathrm{R}_{1}$ without microtrichia. Front tibia with a subapical long seta; tergite IX shoulder-like at the posterior margin. Anal point constricted in the middle and swollen at the apex, with median ridges; anal tergite bands "V" shaped, no fusion in the middle; gonocoxite with a degenerated and small projection in inner distal, bearing setae and microtrichia; gonostylus with a swelling bubble-like protrusion at base and carry microtrichia.

Distribution. China (Hunan, Guangdong, Yunnan); Russian Far East. 


\section{Harnischia sp.1}

Fig. 10

Diagnositic characters. Pupal stage: sternite I with a pair of spinose anterolateral tubercles, dark and developed; tergites III-VI with narrow, posterior robust spines; hook row medially interrupted; segment II-IV with $2 \mathrm{~L}$ setae situated on tubercles; segment VIII without comb or spur.

Materials examined. China: 2P, Jiangxi Province, Shangrao City, Poyang County, Poyang Lake 12.05.2015. W. Liu.

Description. Pupa [n = 2] Total length 5.8-6.0 mm. Exuviae brown.

Cephalothorax (Figs 10A, C-E). Frontal setae 25-30 $\mu \mathrm{m}$ long, fine, arising subapically from conical, 125-150 $\mu \mathrm{m}$ long cephalic tubercles. Thoracic horn plumose, with numerous fine branches (Fig. 10E); basal ring oval (Fig. 10D). Thorax granulose

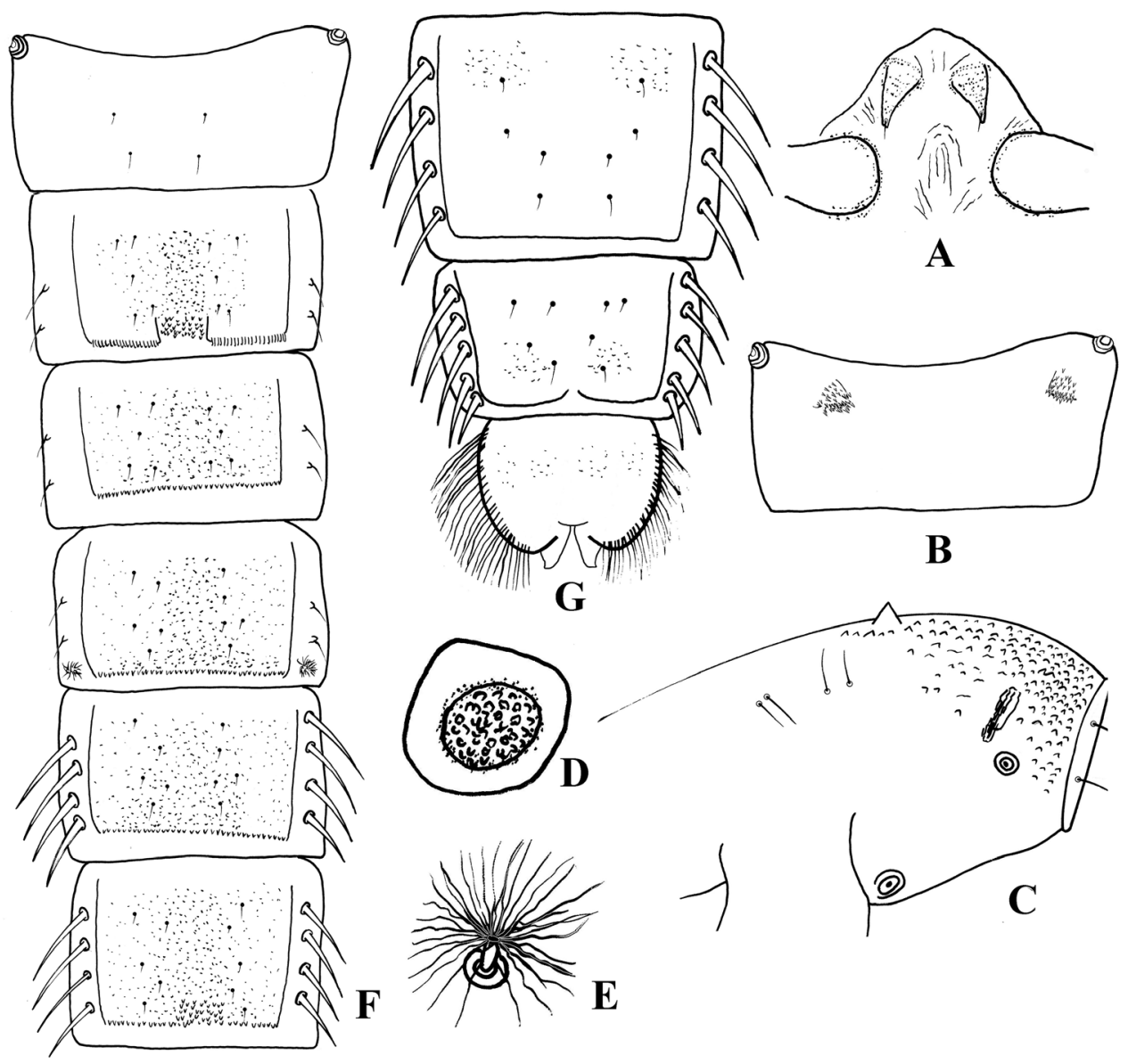

Figures 10. Harnischia sp.1. Pupae. A frontal apotome B sternite I C thorax, lateral view D basal ring $\mathbf{E}$ thorax horn $\mathbf{F}$ tergites I-VI G tergite VII-VIII and anal lobe. 
dorsally, more densely granulose anteriorly. Prealar tubercle low and rounded. Scutal tubercle prominent. Wing sheath without nose; pearl row absent. Two short precorneals, 2 short antepronotals and 4 dorsocentrals present. Lengths of dorsocentrals $(\mu \mathrm{m})$ : 100-105, 80-105, 75-90, 65-90.

Abdomen (Fig. 10B, F-G). Tergite I (Fig. 10F) bare; II with posteromedian group of small points; III-VI with narrow, transverse, posterior band of robust spines; VII with a pair of anterior patches fine shagreen; VIII with a pair of anterior and posterolateral patches of shagreen. Hook row widely interrupted medially. Conjunctives bare. Pedes spurii A present on segment IV; pedes spurii B present on segment I. Sternite I (10 B) with a pair of spinose anterolateral tubercles, dark and well developed. Segment VIII without posterolateral comb or spur. Segment II-IV with 2 strong L setae situated on tubercles; V-VII with 4 LS setae, VIII with 5 LS setae.

Anal lobe (Fig. 10G) 1.75-1.94 $\times$ as long as broad, with complete fringe of 68-72 lamelliform setae. Genital sac $300 \mu \mathrm{m}$ long, extending beyond anal lobe.

Remarks. This species can easily be separated from other known pupa of Harnischia species by the following characters: sternite I with a pair of spinose anterolateral tubercles, dark and well developed; tergites III-VI with narrow posterior robust spines; hook row medially interrupted; segment II-IV with 2 L setae situated on tubercles; anal lobe with complete fringe of 68-72 lamelliform setae.

\section{Key to male adults of known Harnischia species from China}

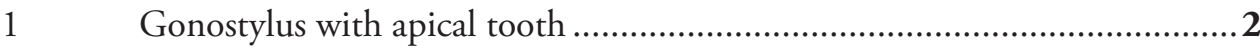

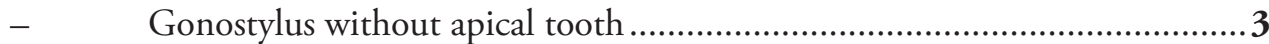

2 Inner margin of gonocoxite with obvious projection; gonostylus longer than gonocoxite, swollen and knife-like at the middle; apical teeth straight

H. curltriata Wang

- Inner margin of gonocoxite with inconspicuous projection; gonostylus shorter than gonocoxite, not swollen at the middle; apical teeth hooked.

H. angularis Albu \& Botnariuc

Gonostylus with inner basal projection

Gonostylus without inner basal projection

Gonocoxite protrudes into vesicular-shape at base

H. turgidula Wang \& Zheng

Gonocoxite slightly protruding, not bulb-like.

5

Anal point taper-shaped, and the apex of anal point sharp

H. fuscimana Kieffer

Anal point parallel-sided, the apex of anal point broad and blunt 
$7 \quad$ Junction of the gonostylus and gonocoxites not as above; anal point swollen in the middle, with median ridges................... H. curtilamellata (Malloch)

- Junction of the gonostylus and gonocoxite shrunken; anal point not swollen in the middle

H. longispuria Wang \& Zheng

\section{Key to pupae of known Harnischia species from China}

1 Sternite I with 1 pair of spinose anterolateral tubercles (Fig. 5B)

- $\quad$ Sternite I with 2 pairs of spinose tubercules on each side, 1 anterolateral and 1 anteromedian (Figs 4B, 10B) H. curtilamellata (Malloch)

2 Pairs of spinose anterolateral tubercles on sternite I brown; segment II-IV with 3 strong $L$ setae H. fuscimana Kieffer

- $\quad$ Pairs of spinose anterolateral tubercles on sternite I dark and well-developed; segment II-IV with $2 \mathrm{~L}$ setae situated on tubercles

Harnischia sp.1

\section{Acknowledgements}

We are grateful to Prof. P. K. Chaudhuri and Dr. A. Mazumdar (Department of Zoology, Burdwan University, India) for kindly providing important information. We also thank the assistance of Dr. A. Shinohara (Department of Zoology, National Science Museum, Tokyo, Japan), who kindly enabled us to examine Sasa type specimens, Dr. P. Cranston, Department of Entomology, University of California, Davis, USA; Dr. G. Maheshwari, School of Entomology, St. John's College, Agra, India for informations and helpful comments; Dr. Leonard Ferrington (University of Minnesota, U.S.A.) provided valuable comments on a previous version of this manuscript; $\mathrm{Mr}$. Bingchun Ji and Mrs. Yufen Li made the slide preparations. Financial support from the National Natural Science Foundation of China granted No. 31672324, 31101653, 31272284, Natural Science Foundation of Tianjin (14JCQNJC14600), Tianjin City High School Science \& Technology Fund Planning Project (20090608), Tianjin City Excellent Young Teachers Fund Planning Project (2013), Undergraduate Training Programs for Innovation and Entrepreneurship (201610065017), and the Tianjin Normal University Talent Introduction Foundation (5RL104) are acknowledged with thanks.

\section{References}

Albu P, Botnariuc N (1966) Les Chironomidea de la riziere de Chirnogi (Oltenitza Roumanie). Verh.1. Int. Symp. Chironomidae, Plön, 25-27.7.1964. Gewäss. Abwäss 41/42: 48-63. Ashe P, Cranston PS (1990) Family Chironomidae. In: Soós A, Papp L (Eds) Catalogue of Palaearctic Diptera (Vol. 2.) - Psychodidae - Chironomidae. Akadémiai Kiadó, Budapest, $113-355$. 
Beck EC, Beck WM (1969) Chironomidae (Diptera) of Florida III. The Harnischia complex (Chironiominae). University of Florida Gainesville. Bulletin of the Florida State Museum (Biological Sciences) 13(5): 277-313.

Chaudhuri PK, Chattopadhyay S (1990) Chironomids of the rice paddy areas of West Bengal, India (Diptera: Chironomidae). Tijdschrift voor Entomologie 133: 149-195.

Chaudhuri PK, Hazra N, Alfred JRB (2001) A checklist of Chironomid midges (Diptera: Chironomidae) of the Indian subcontinent. Oriental Insects 35: 335-372. doi: 10.1080/00305316.2001.10417312

Cranston PS, Martin J (1989) Family Chironomidae. In: Evenhuis NL (Ed.) Catalog of the Diptera of the Australasian and Oceanic Region. Bishop Museum Press 86, 252-274.

Dutta TK, Ali A, Mazumdar A, Chaudhuri PK (1996) Chironomid midges of Harnischia complex (Diptera: Chironomidae) from the Duars of the Himalayas India. European Journal of Entomology 93: 263-279.

Edwards FW (1929) British non-biting midges (Diptera: Chironomidae). Transactions of the Entomological Society of London 77: 279-439. doi: 10.1111/j.1365-2311.1929.tb00692.x

Fittkau EJ, Reiss F (1978) Chironomidae. In: Illies J (Ed.) Limnofauna Europaea (2 ${ }^{\text {nd }}$ edn). Gustav Fischer Verlag, Stuttgart, 404-440.

Freeman P (1954a) Chironomidae (Diptera) from Western Cape Province-III. Proceedings of the Royal Society, London, B 23: 17-25. doi: 10.1111/j.1365-3113.1954.tb00085.x

Freeman P (1954b) Chironomidae (Diptera) from Western Cape Province-IV. Proceedings of the Royal Society, London, B 23: 172-180. doi: 10.1111/j.1365-3113.1954.tb00445.x

Freeman P, Cranston PS (1980) Family Chironomidae. In: Crosskey RW (Ed.) Catalogue of the Diptera of the Afrotropical Region. British Museum (Natural History), London, 175-202.

Goetghebuer M (1923) Noueaux matériaux pour l'étude de la faune des Chironomides de Belgique. $2^{\mathrm{e}}$ note. Annales de Biologie Lacustre 12: 103-120.

Goetghebuer M (1937-1954) Tendipedidae (Chironomidae). B. Subfamilie Tendipedinae (Chironominae). A. Die Imagines. In: Lindner E (Ed.) Die Fliegen der Palaearktischen Region 3, (13c), 1-138.

Hashimoto H (1984) A new species of Harnischia (Dipt. Chironomidae) from Japan. KontyÛ, 52: 262-265.

Hashimoto H, Wongsiri T, Wongsiri N, Tirawa C, Lewvanich A, Yasumatsu K (1981) Chironominae from rice fields of Thailand with description of 7 new species. Thailand Department of Agriculture, Taxonomy Branch, Entomology and Zoology Division, Technical Bulletin 7: 1-47.

Kawai K, Okamoto H, Imabayashi H (2002) Five new chironomid species of five genera from Japan. Medical Entomology and Zoology 53(2): 73-82. doi: 10.7601/mez.53.73_1

Kieffer, JJ (1921) Chironomidea nouveaux ou peu connus de la region paléarctique. Bulletin de la Société d'Histoire naturelle de Moselle 29: 51-109.

Langton PH (1991) A key to pupal exuviae of West Palaearctic Chironomidae. Privately published, Huntingdon, 395 pp.

Makarchenko EA, Makarchenko MA, Zorina OV, Sergeeva IV (2005) Preliminary data on fauna and taxonomy of Chironomids (Diptera, Chironomidae) of the Russian Far East. Vladimir Ya. Levanidov's Biennial Memorial Meetings, 394-420. 
Malloch JR (1915) The Chironomidae or midges of Illinois, with particular reference to the species occurring in the Illinois river. Bulletin of the Illinois State Laboratory of Natural History 10: 275-543.

Murray DA (2015) Glyptotendipes (Heynotendipes) signatus (Kieffer) and Harnischia fuscimanus Kieffer (Diptera, Chironomidae) new to Ireland. Dipterists Digest, Sec. Ser. 22(1): 16.

Oliver DR, Dillon ME, Cranston PS (1990) A catalog of Nearctic Chironomidae. Research Branch Agriculture Canada Publication, 1857/B: 1-89.

Paasivirta L (2014) Checklist of the family Chironomidae (Diptera) of Finland. ZooKeys 441: 63-90. doi: 10.3897/zookeys.441.7461

Pinder LCV (1978) A key to adult males of British Chironomidae the non-biting midges (2 volumes). Freshwater Biological Association Scientific Publication 37: 1-169.

Pinder LCV, Reiss F (1986) The pupae of Chironominae (Diptera: Chironomidae) of the Holarctic region Keys and diagnoses In: Wiederholm T (Ed.) Chironomidae of the Holarctic region - Keys and diagnoses - Part 2 - Pupae. Entomologica Scandinavica Suppl. 28, 299-456.

Rufer MM, Ferrington LC (2007) Key to the Chironomidae Pupal Exuviae in the Twin Cities Metro Area Lentic Waters. Master's Thesis, University of Minnesota, St. Paul, 100 pp. [unpublished]

Sasa M (1989) Studies on the chironomid midges (Diptera, Chironomidae) of Shou River. In: Some characteristics of Nature Conservation within the chief rivers in Toyama Prefecture (The upper reach of Shou River), Toyama Prefect. Envir. Pollut. Res. Center., 26-45.

Sasa M (1990) Studies on the chironomid midges collected from lakes and streams in the southern region of Hokkaido, Japan. Research from the National Inetitute for Environmental Studies 121: 8-76.

Sasa M (1993) Studies on the chironomid midges (Yusurika) collected in Toyama and other area of Japan. Some characteristics of water quality and aquatic organism in the chief lakes in Toyama Prefecture (Lake Nawagaike), 1-142.

Sasa M, Kawai K (1987) Studies on the chironomid midges of Lake Biwa (Diptera, Chironomidae). Lake Biwa Study Monograph 3. Lake Biwa Research Institute Ohtsu, 520, Japan, $1-119$.

Sasa M, Kikuchi M (1986) Notes on the chironomid miodges of the subfamilies Chironominae and Othocladiinae collected by light traps in a rice paddy area in Tokushima (Diptera, Chironomidae). Medical Entomology and Zoology 37: 17-39. doi: 10.7601/mez.37.17

Sasa M, Kikuchi M (1995) Chironomidae (Diptera) of Japan. University of Tokyo Press, 333 pp.

Sasa M, Ogata (1999) Taxonomic studies on the chironomid midges (Diptera, Chironomidae) collected from the Kurobe Municipal Sewage Treatment Plant. Medical Entomology and Zoology 50: 85-104.

Sasa M, Suzuki H, Sakai T (1998) Studies on the chironomid midges collected on the shore of Shimanto River, in April, 1998: Part 1. Description of species of the subfamily Chironomidae. Tropical Medicine 40(2): 47-89.

Sæther OA (1969) Some Nearctic Podonominae, Diamesinae and Orthocladiinae (Diptera: Chironomidae). Bulletin of the Fishers Research Board of Canada 170: 1-154. 
Sæther OA (1971) Nomenclature and phylogeny of the genus Harnishia (Diptera: Chironomidae). Proc. $4^{\text {th }}$ Int. Symp. On Chironomidae, Carleton Univ., 10-12. August 1970. Can. Ent., 103: 347-362.

Sæther OA (1977) Taxonomic studies on Chironomidae Nanocladius, Pseudochironomus, and the Harnischia complex. Bulletin of Fisheries Research Board of Canada 196: 1-143.

Sæther OA (1980) Glossary of Chironomid morphology terminology (Diptera: Chironomidae). Entomologica Scandinavica Supplement 14: 1-51.

Sæther OA, Ashe P, Murray DA (2000) Family Chironomidae. In: Papp L, Darvas B (Eds) Contributions to a Manual of Palaearctic Diptera (with Special Reference to the Flies of Economic Importance) - Appendix. Science Herald, Budapest, 113-334.

Townes HK (1945) The Nearctic species of Tendipedini (Diptera, Tendipedidae (=Chironomidae)). The American Midland Naturalist 34: 1-206. doi: 10.2307/2421112

Wang S, Qian Q, Xie C (1977) Studies on the Chironomidae from the vicinity of Lake Tunghu, Wuchang. Acta Hydrobiologica Sinica 6: 227-240.

Wang X, Zheng L, Ji B (1993) A taxonomic study on Chironominae (Diptera: Chironomidae) from China III. Genus Harnischia Kieffer. Acta Zootaxa Sinica 18(4): 459-465.

Wang X (1999) Harnischia Kieffer from China, with Emendations to the diagnosis of the genus (Diptera: Chironomidae). Aquatic Insects 21: 169-177. doi: 10.1076/aqin.21.3.169.4517

Wang X (2000) A revised checklist of Chironomidae from China (Diptera). In: Hoffrichter O (Ed.) Late $20^{\text {th }}$ Century Research on Chironomidae: an Anthology from 13th International Symposium on Chironomidae. Shaker Verlag, Achen, 629-652.

Yan C, Wang X (2011) A taxonomic discussion on a valid species of Harnischia Longispuria [sic!] Wang \& Zheng, 1993 (Diptera: Chironomidae). In: Wang X, Liu W (Eds) Contemporary Chironomid Studies. Proceedings of the $17^{\text {th }}$ International Symposium on Chironomidae. Nankai University Press, Tianjin, 240-244. 